\title{
Alguns Problemas para a Determinação de um Campo da Fotografia e Novas Distensões Provocadas pela Imagem Digital
}

\author{
Some Problems for Determining the Photography \\ Field and New Distensions Provoked by the Digital \\ Image
}

\author{
CAMI LA MONTEIRO SCHENKEL \\ Universidade Federal do Rio Grande do Sul
}

Resumo: Com uma multiplicidade de usos e processos, a imagem fotográfica parece ter recusado, desde sua invenção, uma definição específica de meio. A essa originária falta de contornos soma-se, agora, a consolidação da tecnologia digital, que redefiniu nossa relação com as imagens. Partindo da ideia de "campo ampliado" apresentada por Rosalind Krauss e escritos recentes sobre a imagem fotográfica, este estudo é motivado por duas questões principais. A primeira, "É possível circunscrever a fotografia dentro de um campo, mesmo que ampliado?", serve como provocação para balizar a natureza múltipla do meio, que desafia definições essencialistas. A complexidade da pergunta certamente extrapola os limites deste artigo, mas, a partir dessa pontuação inicial, desenvolve-se uma segunda pergunta, "Como a fotografia digital se relaciona com as diferentes práticas reunidas sob o nome fotografia?", a fim de investigar as transformações recentes em uma abordagem que evita o traçado de definições absolutas e limites instransponíveis.

Palavras-chaves: Fotografia. Campo expandido. Imagem digital.

Abstract: Characterized by multiple uses and processes, the photographic image seems to have refused, since its invention, a specific definition as a medium. The consolidation of the digital technology, which has redefined our relation to images, has added up to this originary lack of outlines. Based on the idea of "expanded field" presented by Rosalind Krauss and recent writings about photography, this study is motivated by two main questions. The first one, "Is it possible to circumscribe photography in a field, even an expanded one?", is a trigger to outline the multiple nature of the medium, which challenges essentialist definitions. Its complexity certainly exceeds the limits of this article but, following these initial remarks, a second question is developed, "How does digital photography relate to the different practices gathered under the term photography?", in order to investigate the recent transformations in an approach which avoids absolute definitions and insurmountable boundaries.

Keywords: Photography. Expanded field. Digital image.

SCHENKEL, Camila Monteiro. Alguns Problemas para a Determinação de um Campo da Fotografia e Novas Distensões Provocadas pela Imagem Digital. Informática na Educação: teoria \& prática, Porto Alegre, V. 21, n.1, p. 13-18, jan./abr. 2018. 
Os limites são essas marcas, às vezes invisíveis e outras insuperáveis, que separam o possível do pensável

Rosa Olivares

Em sua curta história de menos de 200 anos, a fotografia passou por uma série de transformações técnicas que mudaram radicalmente a relação do homem com as imagens. Essas mudanças, ao mesmo tempo rápidas e significativas, despertaram desde o início respostas apaixonadas, como a célebre crítica de Charles Baudelaire a respeito do Salão da Academia Francesa de Belas-Artes de 1859. Desde seu surgimento, essa invenção de muitos criadores, muitos nomes e muitos processos técnicos nos convocou repetidamente a rever limites e definições, colocando em xeque os conceitos estabelecidos de representação, arte, documento e autor.

Desde o final dos anos 1990, o debate teórico sobre a fotografia encontra-se, novamente, em um desses momentos de redefinição. As transformações proporcionadas pela tecnologia digital levaram muitos autores a rever suas convicções sobre as fronteiras da ideia de fotografia. Algo novo, ainda não inteiramente compreendido, está substituindo uma tecnologia e um processo familiares, mas avaliar com segurança o impacto dessas mudanças ainda é um desafio. Mas afinal de contas, o que é uma fotografia? Esses contornos, antes da chegada do digital, encontravam-se assim tão evidentes? Existiam qualidades tão específicas que definiam a fotografia como um meio e que, agora, foram radicalmente abaladas?

Os escritos sobre fotografia publicados a partir dos anos 1980 tentaram, de diferentes formas, determinar e analisar o que seria "A Fotografia". A essência do processo fotográfico foi definida por Roland Barthes (2012) pelo isso-foi, uma articulação especial entre realidade e passado; por Philippe Dubois (1998) pelo ato fotográfico, a relação com o real a partir do momento de produção da imagem; e por Vilém Flusser (2002) por meio da relação entre o usuário e o aparelho. Todas essas conceituações tornaram mais complexo o modo como olhamos para fotografias, mas falharam em estabelecer seus limites. Como encaixar todas as imagens fotográficas em um único enquadramento fixo? Tornar à ideia de campo expandido proposta pela crítica norte-americana Rosalind Krauss no final dos anos 1970, uma noção que enfatiza aspectos funcionais e relacionais em vez de substanciais, talvez possa ajudar nesse momento de indefinição.

O artigo A escultura no campo ampliado foi publicado pela primeira vez na revista October em 1979. Até hoje, é um texto referencial para a reflexão sobre o embate entre a ideia moderna de especificidade da arte e a multiplicação dos meios e práticas artísticas observada a partir dos anos 1960. Logo no início do texto, após uma breve descrição da obra Perimeters/Pavillions/Decoys, de Mary Miss, Krauss afirma que "nos últimos 10 anos coisas realmente surpreendentes têm recebido a denominação de escultura" (2008, p. 129). Diante de manifestações tão heterogêneas como "corredores estreitos com monitores de TV ao fundo; grandes fotografias documentando caminhadas campestres; espelhos dispostos em ângulos inusitados em quartos comuns e linhas provisórias traçadas no deserto" (2008, p. 129), a 
autora se propõe a pensar sobre os motivos que levavam a crítica da época a insistir em considerar uma gama tão ampla de trabalhos artísticos a partir da distensão do conceito de escultura.

Krauss critica o uso cada vez mais elástico desse termo, denunciando a ideia historicista de causa e efeito implicada por tal manobra: “o novo é mais fácil de ser entendido quando visto como uma evolução de formas do passado" (2008, p. 129), como explica a autora. Para a crítica, tal mascaramento acaba ocultando diferenças e transformando a diversidade em um campo naturalizado e homogêneo. Em seu lugar, propõe a definição de uma lógica do meioque não se cristalizaria em uma essência ou em um conjunto de especificidades, mas seria definida, o invés, por um jogo de oposições construído a partir de um quadrado lógico. Ao perceber que a escultura dos anos 1960 se caracterizava pelo que considera uma ausência ontológica, uma vez que as práticas correntes poderiam ser melhor definidas em termos de negatividade (nãopaisagem, não-arquitetura), a autora propõe que seu estudo seja feito a partir da estrutura do grupo de Klein, uma expansão que transforma oposições binárias em um campo quaternário no qual a relação entre os pares iniciais é espelhada e ampliada.

Figura 1 - Diagrama de A escultura no campo ampliado

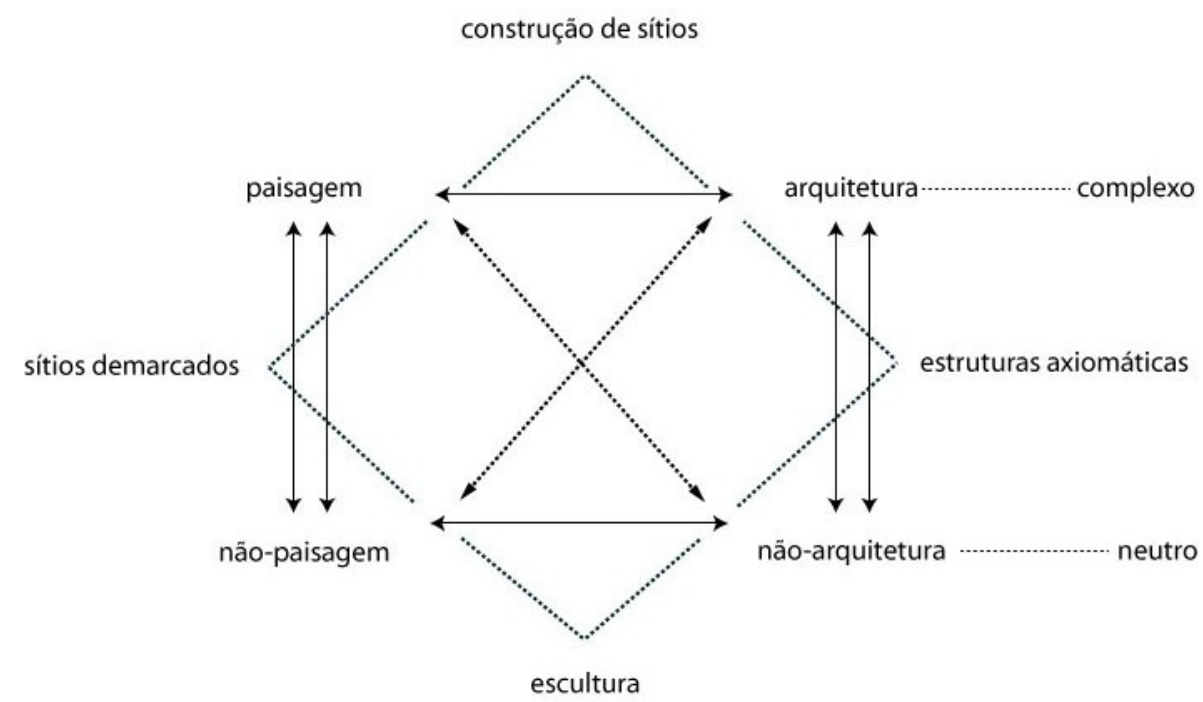

Fonte: desenho elaborado pela autora a partir do artigo de Krauss

Como mostra a figura 1, no vértice inferior do diagrama temos o termo escultura, posicionado entre aquilo que não é nem paisagem, nem arquitetura. Conforme proposto por Krauss, outras relações entre paisagem, arquitetura e seus negativos podem ser utilizadas para compreender as práticas artísticas alternativas observadas a partir dos anos 1960, como a construção de sítios, que seria ao mesmo tempo paisagem e arquitetura, ou a demarcação de 
sítios, que se posicionaria entre a paisagem e a não paisagem. Em uma abordagem que aproxima o natural e o cultural, a autora chega, dessa forma, a uma espécie de mapa expandido da produção artística de sua época relacionada ao espaço, englobando categorias até então excluídas do campo da arte.

Para Regis Durand, o excesso de estruturalismo da proposta de Krauss é compensado pelos resultados de sua operação que, ao considerar a história de um campo, consegue ir além da história do meio defendida pela crítica formalista que dominou o discurso teórico em meados do século XX (DURAND, 2003). Durante a alto-modernismo, a busca pela determinação do que caracterizava cada meio artístico funcionou como uma ferramenta para definir limites e dar solidez à produção do período, especialmente a pintura, contribuindo para sua legitimação. A estratégia garantia o território da disciplina atuando a partir de seu interior e os limites serviam para separar a arte ou determinada linguagem artística do genérico e do não artístico. A base dessas operações era o pensamento de Clement Greenberg, crítico norte-americano responsável pela consolidação da abordagem formalista como principal forma de compreender a arte produzida após as vanguardas históricas. Em um de seus textos inaugurais, Rumo a um mais novo Laocoonte, publicado originalmente na revista literária Partisan Review em julho de 1940, Greenberg já sintetizava suas ideias a respeito da necessidade de delimitação da especificidade de cada arte e o consequente processo de purificação e autonomização de cada linguagem:

[...] as artes de vanguarda nos últimos cinquenta anos alcançaram uma pureza e uma delimitação radical de seus campos de atividade sem exemplo anterior na história da cultura. As artes encontram-se agora em segurança, cada uma dentro de suas legítimas fronteiras, e o livre comércio foi substituído pela autarcia. A pureza na arte consiste na aceitação - a aceitação voluntária das limitações do meio de cada arte específica (GREENBERG, 1997, p. 53).

As reflexões apresentadas por Krauss (2008) em A escultura no campo ampliado revisitam o próprio percurso teórico da autora, iniciado sob as asas de Greenberg, recolocando o problema da especificidade da arte. O artigo chama a atenção tanto para a importância dos limites de uma disciplina quanto para a valorização daquilo que escapa desses contornos - ou seja, para a relação de um meio com aquilo que lhe é exterior. Produzido dentro do contexto dos primeiros anos de pós-modernismo no campo da arte, o texto é marcado por um ambiente de crise, podendo ser visto como uma resposta da autora à situação de pluralismo que começava a se delinear. Resistindo à ideia de um vale-tudo artístico e teórico, Krauss propõe a expansão do conceito de meio autônomo e fechado para a ideia de um campo heterogêneo, marcado por relações de semelhança e contraste entre seus componentes. Essa operação, no entanto, é desenhada dentro da estrutura fixa de um quadrado, que determina o número de elementos que compõem o campo e estabelece as formas de relação entre eles, atribuindo-lhes posições estáveis. Além disso, esse jogo de relações e oposições só poderia ser traçado a partir da delimitação inicial de uma definição de escultura. Como a própria autora resume, o campo

${ }^{1}$ Como exemplos para auxiliar a compreensão das categorias propostas por Krauss, poderíamos considerar as operações que Robert Smithson realiza na paisagem como construção de um sítio, as marcas deixadas por Richard Long durante suas caminhadas como demarcação de um sítio e o trabalho de empacotamento de prédios realizado por Christo e JeanneClaudecomo uma estrutura axiomática, categoria que se define entre a arquitetura e a não-arquitetura. 
ampliado “é gerado pela problematização do conjunto de opções, entre as quais está suspensa a categoria modernista escultura" (KRAUSS, 2008, p. 135).

A fotografia, no entanto, esteve sempre nos limites de muitas disciplinas, transitando entre a esfera artística e a científica, o documental e o ficcional, o público e o privado. Estamos cercados de uma multiplicidade de imagens fotográficas, múltiplas não apenas por uma questão de número, mas pela diversidade de modos como são produzidas, exibidas e percebidas - cada uma delas ligada a contextos, visões e sentidos distintos. Em meio a uma produção de mais de um bilhão de fotografias por semana (FRIZOT, 2012, p. 21), a diversidade de usos e funções da imagem fotográfica aponta para a dificuldade da delimitação da categoria fotografia.

Desde seus primórdios, o meio se caracterizou por diferentes inventores e processos, assim como pela articulação com diferentes linguagens, entre elas a pintura, a escrita e o cinema. Para além de uma definição da fotografia com contornos precisos, pode-se pensar em um universo de diferentes imagens técnicas, parcialmente automáticas, reproduzíveis, que registram de alguma forma a incidência da luz sobre os objetos. Um tecido cultural em vez de um objeto fixo, como sugerido por Michel Frizot na passagem abaixo e também em sua nova história da fotografia: ${ }^{2}$

\begin{abstract}
A expansão da técnica fotográfica em 1839 e o progresso sucessivo decorrente geraram múltiplas práticas as quais produziram, gradativamente, uma cultura fotográfica, apoiada na criação de 'objetos' fotográficos não limitados a uma categoria de imagem [...]. Seu tecido cultural se constitui, de fato, pelo grande número de operadores, de produtores de imagens, de divulgadores, de detentores de fotografias, enfim, de admiradores, e também pelo grande número de imagens fotográficas (FRIZOT, 2012, p. 21).
\end{abstract}

O campo da fotografia seria, portanto, inespecífico ou expandido desde seu início? Até mesmo seus determinantes técnicos podem ser colocados em dúvida: a fotografia de Louis Daguerre, por exemplo, não envolvia negativos nem a ideia de reprodutibilidade. O processo inventado por William Fox Talbot, por outro lado, possibilitou a obtenção de cópias mas resultava em imagens menos nítidas. Se em 1850 “fotografia” era uma denominação genérica que englobava processos em papel, vidro ou metal, combinados a diferentes substâncias químicas, com o tempo, o termo pareceu se unificar e solidificar (FRIZOT, 2012). Essa aparente homogeneização funciona para fins práticos mas encobre, como Frizot aponta, a diversificação cada vez maior que permeia os usos da imagem fotográfica. Tampouco considera as técnicas e invenções particulares que possibilitaram produtos como a fotografia astronômica, a microfotografia, a fotografia colorida, a cronofotografia, entre tantas outras. Cristalizou-se um único termo, mas isso não reflete necessariamente uma unificação de processos e práticas. Os desdobramentos posteriores do meio colocariam, ainda, mais um problema em relação à determinação do campo da fotografia. Ele abarcaria as imagens técnicas produzidas posteriormente, como o cinema, o vídeo e a imagem digital? Podemos falar desses meios sem nos referirmos, também, ao fotográfico?

\footnotetext{
${ }^{2}$ Ver FRIZOT, Michel (Ed.). Nouvelle Historie de la Photographie. Paris: Adam Biro/Bordas, 1994.
} 
Com as modificações provocadas nas últimas décadas pela difusão da fotografia digital, os limites do termo fotografia voltaram à discussão com nova força. As pesquisas na área de exploração espacial de meados da década de 1960 colocaram a necessidade de desenvolver imagens fotográficas que não dependessem do suporte físico do filme e pudessem, dessa forma, ser transmitidas à longa distância. Trinta anos mais tarde, os desdobramentos dessas investigações começaram a se tornar acessíveis para um público mais amplo, consolidando os dispositivos digitais como a principal forma de gerar imagens fotográficas da atualidade. Muitos autores apontam uma transformação radical na passagem da fotografia química para a fotografia digital, chegando até mesmo a questionar se ainda deveríamos utilizar o mesmo termo para denominá-las.

No início dos anos 1990, ao mesmo tempo em que a imagem digital começava a penetrar na vida cotidiana, historiadores da arte e teóricos da comunicação já colocavam em dúvida a relação entre a fotografia tradicional, baseada em um processo químico, e a nova tecnologia de produção de imagens que estava se afirmando. A opção pela palavra pósfotografia já aparece no título de um livro publicado por W. J. T. Mitchell em 1992. Na introdução de The Reconfigured Eye: Visual Truth in the Post-Photographic Era, o teórico norteamericano descrevia o que caracterizava como uma ruptura com o sistema de imagens anterior. Assim como não se podia simplesmente considerar um automóvel como uma carruagem sem cavalos ou o rádio como um telégrafo sem fios, Mitchell defendia firmemente que a imagem digital não deveria ser vista como um simples processo de evolução de uma técnica anterior.

Para o autor, a fotografia digital era tão diferente da fotografia tradicional quanto uma fotografia era de uma pintura, uma vez que a nova invenção se constituía como um tipo de representação digital, ou seja, de traços discretos, enquanto sua versão anterior funcionava como uma representação análoga, com traços contínuos. A ideia de processamento, de possibilidade de manipulação de informação, apresentava-se como um aspecto central dessa novamodalidade de imagens:

\begin{abstract}
Uma imagem digital pode ser em parte uma fotografia escaneada, em parte um desenho de perspectiva sintetizado pelo computador e em parte uma 'pintura' eletrônica - tudo delicadamente amalgamado em um todo aparentemente coeso. Pode ser fabricada de arquivos encontrados, restos de discos, detritos do ciberespaço. Os criadores de imagens digitais dão sentido e valor para readymades computacionais por meio de apropriação, transformação, reprocessamento e recombinação: nós entramos na era da eletrobricolagem (MITCHELL, 1992, p. 6). ${ }^{3}$
\end{abstract}

Mitchell acreditava que no início dos anos 1990 estávamos novamente diante de um momento no qual a cristalização de uma nova tecnologia provocava mudanças profundas nas práticas culturais e sociais, assim como fizera a fotografia química em meados do século XIX. Para ele, a fotografia tradicional podia ser declarada morta, ou radicalmente deslocada, como ocorrera com a pintura 150 anos antes. Essa mudança no sistema de produção também afetaria a estabilidade das imagens, que não deveriam mais ser vistas.

\footnotetext{
${ }^{3}$ As citações de obras em língua estrangeira são traduções próprias.
} 
[...] nem como objetos rituais (como serviram as pinturas religiosas) nem como objetos de consumo de massa (como são as fotografias e as imagens impressas na célebre análise de Walter Benjamin), mas como fragmentos de informação que circulam nas redes de alta velocidade que agora circundam o mundo e que podem ser recebidas, transformadas e recombinadas como DNA para produzir novas estruturas intelectuais com sua própria dinâmica e valor (MITCHELL, 1992, p. 51).

A ideia de que estamos entrando em uma nova era de imagens, completamente diferentes da fotografia de base química que marcou o período industrial, também é defendida em publicações mais recentes como After Photography, de Fred Richtin (2008), e La cámara de Pandora: La fotografí@ después de la fotografia, de Joan Fontcuberta (2010). Ritchin, assim como Mitchell, destaca a maleabilidade da nova forma de fotografia, que se torna um mosaico flexível, facilmente combinável com outras imagens, textos e sons. Em sua versão digital, o registro fotográfico seria apenas um ponto de partida para operações posteriores realizadas por diferentes agentes. Segundo o autor, “a fotografia se converte na investigação inicial, em um esboço da imagem, tão vulnerável agora à modificação quanto sempre foi à recontextualização" (RITCHIN, 2010, p. 43).

Em uma publicação editada poucos anos depois, Joan Fontcuberta defende, de maneira similar, a ruptura introduzida pelo sistema digital no processo de produção de imagens técnicas. Para o fotógrafo catalão, a substituição dos sais de prata por uma retícula de pixels provisoriamente ordenados introduz uma nova categoria de imagens que, pela diferença radical de natureza em relação ao processo fotográfico tradicional, poderiam ser consideradas "pósfotográficas". Essa mudança colocaria a fotografia digital no plano da pintura e da escultura, representações que podem ser manipuladas em suas unidades mínimas, ponto a ponto, e que possuem autonomia em relação ao referente.

No entanto, como apontam André Rouillé (2008) e Claudio Marra (2006), mesmo com todas essas mudanças, a fotografia digital ainda coincide em muitos aspectos e usos com 0 processo ótico-químico que Ihe deu origem. Marra, com uma pitada de provocação, chega a afirmar que a fotografia digital não existe. As centenas de arquivos de imagens que temoshoje em nossos computadores e celulares seriam apenas fotografias digitalizadas, uma vez que o processo de transformação do registro da luz em código binário não ocorre no instante em que a situação de luz é captada, mas apenas em um segundo momento, quando as informações de luz registradas pelo sensor como cargas elétricas são processadas pelo ADC (Analogue to Digital Converter), um circuito integrado que atribui a elas um número binário (MARRA, 2006). O historiador da arte italiano destaca, ainda, os usos e convenções que envolvem a prática fotográfica contemporânea, que, mesmo que acelerados e multiplicados, ainda são muito similares aos da fotografia tradicional, permanecendo ligados à ideia de registro de um objeto.

Já Rouillé apresenta uma posição intermediária ao classificar a fotografia digital como uma outra fotografia dentro da fotografia, considerando que "ela se situa dentro do quadro da fotografia, mas representa questões técnicas diferentes, representa um regime de verdade completamente diferente", marcado por uma velocidade de circulação e divulgação próprias. “Há uma ruptura de natureza em relação à fotografia tradicional, de natureza material e 
imaterial" (ROUILLÉ, 2008, p. 28), uma vez que a maior parte das fotografias produzidas atualmente circula apenas em telas. A fotografia digital seria, portanto, uma forma desmaterializada e de rápida produção e circulação, mas ainda situada dentro do campo da fotografia.

Para podermos estabelecer uma posição em relação a esses discursos - os que incorporam a fotografia digital no âmbito mais amplo dos processos de criação de imagens técnicas surgidos a partir de meados do século XIX e os que, ao contrário, estabelecem uma fronteira divisória irredutível entre a fotografia química e a fotografia digital - serão revisadas, a seguir, algumas diferenças e continuidades básicas entre os dois processos. Como primeiro diferencial, poderíamos citar o desaparecimento do negativo, questão de certa forma já antecipada nos anos 1960 e 1970 pela imagem instantânea das máquinas Polaroid. Apesar de continuar operando em função da luz refletida por objetos, o sensor de uma câmera digital não é irreversivelmente afetado por essa luminosidade. A partir de medições e codificações, ele gera um arquivo que depois pode ser visualizado como imagem. O sensor acolhe apenas temporariamente a imagem gerada pela incidência da luz sobre objetos, podendo ser utilizado para gerar uma infinidade de fotografias.

Perde-se também a questão do suporte material: a tecnologia digital descola a imagem fotográfica da superfície específica do filme e do papel, em um processo de desmaterialização que privilegia, em lugar da permanência, o compartilhamento e a transmissão. A imagem, na maioria das vezes, não é mais fixada definitivamente em um suporte, mas passa a ser temporariamente visualizada em dispositivos eletrônicos. Para Vilém Flusser, o que distinguia a fotografia de outras imagens técnicas era justamente a portabilidade e a autonomia proporcionadas por sua materialização em papel, que permitia sua distribuição de maneira arcaica (FLUSSER, 2002). A fotografia digital, ao contrário, por depender de aparelhos para ser visualizada, se aproxima da forma de circulação do cinema e do vídeo. Com a popularização da comunicação digital e o desenvolvimento de dispositivos cada vez mais portáteis, a imagem fotográfica perde o substrato físico do filme e da folha de papel para existir como uma forma errante, que migra de tela em tela, podendo ser sucessivamente ampliada, compactada e transformada. Se a fotografia analógica pode ser vista como um modo de "produzir permanências", em sua versão digital "desaparecem as ancoragens e pontos fixos" (ROUILLÉ, 2009, p. 454).

A fotografia digital também ampliou e facilitou a tradição de manipulação de imagens, acentuando a maleabilidade das imagens técnicas. Nesse contexto, a pós-produção ganha cada vez mais importância, convertendo a imagem gerada pelo clique em uma espécie de ponto de partida que pode ser aprimorado, trabalhado e retrabalhado para diferentes fins. Operações de montagem e retoques que, convém lembrar, já podiam ser feitas no processo de revelação e ampliação da fotografia de base química, mas que exigiam conhecimentos e uma estrutura técnica menos difundidos. Como consequência, temos um gradual abalo no regime de verdade dentro do qual a imagem fotográfica costumava operar na maior parte de seus usos cotidianos. 
Trabalhos como Fictitious Portraits, de Keith Cottingham (1993) e Orogènisi, de Joan Fontcuberta (2002-2006), ${ }^{4}$ entre tantos outros, valem-se da possibilidade de criação da imagem digital não a partir de um único referente real, mas da combinação e da transformação de múltiplas imagens de diferentes origens. Cada vez mais, aparência e rastro, ficção e indício se misturam, evidenciando a fragilidade do mito modernista que via a fotografia como um espelho da realidade.

Ao mesmo tempo, o tão comentado estatuto de verdade da fotografia parece, de alguma forma, resistir à proliferação da manipulação de imagens proporcionada pelo desenvolvimento e a popularização de softwares de edição como o Photoshop, lançado comercialmente em 1990. Mesmo em sua forma digital, continuamos produzindo, compartilhando e armazenando fotografias para fins de registro, documentação e memória. As imagens digitalmente construídas por Fontcuberta e por Cottingham, apesar de não registrarem uma paisagem real ou uma pessoa específica, continuam a simular um registro fotográfico, respeitando sua aparência e seus códigos.

Uma terceira mudança que deve ser considerada, talvez a mais significativa entre aquelas introduzidas pela tecnologia digital, é o assombroso aumento nas esferas de produção e circulação de imagens fotográficas. Se por um lado podemos dizer que o processo de transformação do mundo em imagens iniciou-se no final do século XIX, quando a fotografia se tornou um fenômeno de massas, por outro, a imagem digital, combinada ao desenvolvimento da Internet, colocou a questão em um novo patamar.

A fotografia digital mudou definitivamente o modo como criamos e compartilhamos imagens, assumindo um papel cada vez maior na comunicação. As imagens se tornaram mais banais e onipresentes, perdendo o caráter de excepcionalidade antes reservado à fotografia, inicialmente destinada a celebrar momentos marcantes como nascimentos, casamentos e aniversários. Hoje registramos qualquer pessoa, objeto, evento ou experiência em centenas de variações, em quantidades e velocidades tão grandes que impossibilitam que essas imagens sejam devidamente avaliadas - nunca produzimos tantas fotografias e ao mesmo tempo nunca olhamos tão pouco para elas. Como alerta André Rouillé,

o digital proporciona à fotografia a disponibilidade imediata de clichés e a possibilidade de cancelá-los sem demora ou complicação. Essas facilidades, somadas a um alto nível de automatização e um custo de produção zero, criam as condições de emergência de uma estética da rapidez, da profusão, mas também da desatenção (ROUI LLÉ, 2014, p. 1).

Essa sensação de empobrecimento da experiência da fotografia, no entanto, não é algo exclusivo de nosso tempo, mas um sintoma também observável em outros momentos nos quais os processos de fabricação e circulação de imagens passaram por grandes transformações. No

\footnotetext{
${ }^{4}$ Fictitious Portraits é uma série de fotografias que apresenta retratos imaginários criados a partir da combinação de técnicas como modelagem, desenho, pintura digital e montagem. Já as paisagens fantasiosas, mas ao mesmo tempo verossímeis de Orogènisi são criadas por um software de uso militar que gera ilustrações geográficas capazes de simular a tridimensionalidade a partir de informações cartográficas. Em vez de mapas, no entanto, Fontcuberta alimenta esse software com obras conhecidas da história da arte, como pinturas de Caspar David Friedrich, William Turner e Gustave Courbet ou fotografias de Eugène Atget e Alfred Stieglitz.
} 
ensaio Pequena história da fotografia, de 1931, Walter Benjamin já relacionava o aprimoramento das técnicas fotográficas e sua consequente transformação em um produto de massas ao declínio de sua aura. É apenas nas imagens produzidas no primeiro decênio após o anúncio oficial da fotografia, como na produção de David Octavius-Hill, que Benjamin vê surgir algo de estranho e novo, aquela

pequena centelha do acaso, do aqui e agora, com a qual a realidade chamuscou a imagem, [...] lo lugar imperceptível em que o futuro se aninha ainda hoje em minutos únicos, há muito extintos, e com tanta eloquência que podemos descobri-lo, olhando para trás. (BENJAMIN, 2012, p. 94).

Benjamin destaca nas fotografias do período uma articulação inédita e mágica, capaz de revelar nosso inconsciente ótico, mas que logo foi perdida em nome das funções cotidianas assumidas por esse tipo de imagem.

Menos de 50 anos após a publicação do ensaio de Benjamin, o campo da fotografia foi novamente abalado e reorganizado pelos avanços na área da informática e da eletrônica. Ainda nos anos 70, ao comentar sobre o potencial de transformação que esse novo tipo de imagem poderia trazer para o campo da cultura, A. D. Coleman chamava a atenção para a necessidade de uma educação para as imagens e um papel mais ativo em relação a elas. "A comunicação visual é vivida por muitos, mas praticada por poucos" (1998, p. 40), o que gera uma perigosa situação de concentração de poder e possibilidade de manipulação. "A única solução é autodefesa cultural. Devemos pegar as ferramentas com nossas próprias mãos" (COLEMAN, 1998, p. 48).

Atualmente, com o desenvolvimento e o barateamento dessas primeiras máquinas fotográficas digitais e, acima de tudo, com a incorporação de câmeras aos telefones celulares, o cenário é bastante diferente. Relatórios recentes de empresas do ramo da tecnologia e da comunicação apontam para a concretização da previsão de que, em 2015, o número de celulares cadastrados ultrapassaria o número de habitantes da terra. Dos aparelhos telefônicos vendidos no primeiro trimestre de 2015, cerca de 75\% foram smartphones, ou seja, dispositivos capazes de produzir e compartilhar instantaneamente uma infinidade de imagens. ${ }^{5}$ A criação e a circulação de imagens continuam, evidentemente, perpassadas por estruturas de poder e ideologias, mas, ao sermos cada vez mais convocados a produzi-las e compartilhá-las, novas significados e usos podem ser descobertos.

O fato da ideia de uma pós-fotografia resistir por mais de uma década indica que, mesmo depois da completa afirmação da fotografia digital, ainda estamos desorientados em relação às múltiplas possibilidades que se abrem para o campo. O anúncio do encerramento das atividades fotográficas da Kodak em 2012 - empresa que marcou a popularização da fotografia amadora com as câmeras portáteis e automáticas produzidas a partir do final do século XIX seria uma evidência de que o que chamamos hoje de fotografia não tem mais ligação com as imagens técnicas que transformaram a visualidade do mundo moderno? Estamos diante de algo completamente novo, que requer novas categorias e conceitos para ser compreendido, ou a

${ }^{5}$ Ver, por exemplo, o relatório sobre mobilidade da Ericsson, disponível em:

<http://www.ericsson.com/res/docs/2015/ericsson-mobility-report-june-2015.pdf>, acesso em julho de 2015. 
crítica fotográfica se apressa em estabelecer um novo ponto de origem para as imagens que produzimos atualmente, destacando o ineditismo e o aspecto revolucionário da fotografia digital em detrimento da história e até mesmo dos usos correntes do meio? Nesse caso, estaríamos observando um fenômeno oposto ao denunciado por Rosalind Krauss em A escultura no campo expandido. Se em seu artigo de 1972 Krauss criticava os teóricos da arte que estendiam e flexibilizavam a categoria da escultura para tornar as novas práticas artísticas mais palatáveis a suas audiências, agora talvez seja necessário questionar os anúncios de ruptura completa que acompanham a afirmação da imagem digital. Esses tendem a ver a fotografia digital de maneira isolada, como um meio específico, e a ignorar suas relações com a fotografia de base química, desconsiderando a diversidade da própria história das imagens técnicas para anunciar uma nova era.

Um dos principais argumentos de A escultura no campo ampliado é a constatação de que, após o modernismo, a prática artística não pode mais ser definida apenas em relação a um determinado meio de expressão, como a escultura, “mas sim em relação a operações lógicas dentro de um conjunto de termos culturais para o qual vários meios [...] possam ser usados" (KRAUSS, 2008, p. 136). As práticas fotográficas tampouco devem ser definidas apenas em relação a sua forma mais recente, a fotografia digital, mas precisam ser pensadas dentro de um campo mais amplo. Um campo com tantas pontas e variações que talvez nunca possa ser circunscrito por um simples quadrado, mas que demanda figuras assimétricas de múltiplas pontas, em constante reconfiguração. Em vez de insistir em manter as tecnologias em compartimentos isolados, aceitar o desafio de pensar as relações entre a fotografia estereoscópica e as projeções 3D, a Polaroid e a fotografia de celular, o Photoshop e a fotomontagem, o carte-de-visite e o Snapchat, por exemplo, pode ajudar-nos a compreender melhor o momento em que vivemos e até mesmo a projetar outros futuros possíveis para nossas imagens.

\section{Referências}

BARTHES, Roland. A Câmara Clara: nota sobre a fotografia. Lisboa: 70, 2012.

BENJ AMIN, Walter. Pequena História da Fotografia. In:__. Magia e Técnica, Arte e Política: ensaios sobre literatura e história da cultura. São Paulo: Brasiliense, 2012.

COLEMAN, A. D. The Digital Evolution: visual communication in the eletronic age - essays, lectures and interviews, 1967-1998. Tucson: Nazraeli, 1998.

DUBOIS, Philippe. O Ato Fotográfico e Outros Ensaios. Campinas: Papirus, 1998.

DURAND, Régis. Autonomía e Heteronomía no Campo Fotográfico Contemporáneo. In: AMELUNXEN, Hubertus von. Alén dos Límites: a fotografia contemporánea. Santiago de Compostela: Centro Galego de Arte Contemporánea, 2003.

FLUSSER, Vilém. Filosofia da Caixa Preta: ensaios para uma futura filosofia da fotografia. Rio de Janeiro: Relume Dumará, 2002.

FONTCUBERTA, Joan. O Beijo de Judas: fotografia e verdade. Barcelona: Gustavo Gili, 2010.

A Câmera de Pandora: a fotografi@ depois da fotografia. São Paulo: Gustavo Gili Brasil, 2014.

FRIZOT, Michel (Ed.). Nouvelle Historie de la Photographie. Paris: Adam Biro/Bordas, 1994.

Fotografia: um destino cultural. In: SANTOS, Alexandre; CARVALHO, Ana (Org.). Imagens: arte e cultura. Porto Alegre: UFRGS, 2012. 
GREENBERG, Clement. Rumo a um Mais Novo Laocoonte. In: FERREIRA, Glória; COTRIM, Cecília (Org.). Clement Greenberg e o Debate Crítico. Rio de Janeiro: Funarte; Jorge Zahar, 1997.

KRAUSS, Rosalind. A Escultura no Campo Ampliado. Arte e Ensaios, Rio de Janeiro, ano 15, n. 17, 2008.

MARRA, Claudio. L'Immagine Infedele: la falsa rivoluzione della fotografia digitale. Milano: Bruno Mondadori, 2006.

MITCHELL, W. J. T. The Reconfigured Eye: visual truth in the post-photographic era. Cambridge: MIT, 1992.

OLIVARES, Rosa. Os Limites da Fotografia: cartografias da fotografia contemporânea. In: AMELUNXEN, Hubertus von. Alén dos Límites: a fotografia contemporánea. Santiago de Compostela: Centro Galego de Arte Contemporánea, 2003.

RITCHIN, Fred. Después de la Fotografía. México: Oceano, 2010.

ROUILLÉ, André. A Fotografia: entre documento e arte contemporânea. São Paulo: SENAC, 2009.

Fotografia e Arte Contemporânea. In: FATORELLI, Antonio (Org.). Fotografia e Novas Mídias. Rio de Janeiro: FotoRio, 2008.

La Photo Numérique Mobile: une esthétique autre. Paris Art, Paris, n. 445, 22 maio 2014. Disponível em: <http://www. paris-art.com/art-culture-France/la-photo-numerique-mobile-une-esthetiqueautre/rouille-andre/437.html\#haut>. Acesso em: jul. 2015.

Recebido em fevereiro de 2016

Aprovado para publicação em abril de 2016

Camila Monteiro Schenkel - Universidade Federal do Rio Grande do Sul - UFRGS, Porto Alegre, Brasil, camilaschenkel@gmail.com 